\title{
F.E.E.L.I.N.G.C.A.L.L.E.D.L.O.V.E: UNA APROXIMACIÓN A LA TEORÍA DE LA CANCIÓN POP
}

\author{
Constanza ABEILLÉ \\ Universitat Autònoma de Barcelona \\ ConstanzaAlicia.Abeille@e-campus.uab.cat
}

\section{Introducción}

$\mathrm{P}$ ara comenzar con un análisis de la canción, en el contexto de los estudios culturales aplicados a la música popular contemporánea, debemos tener en cuenta dos puntos de vista: uno centrado en el momento de la producción y otro desde la teoría de la recepción. Esta primera distinción es fundamental para comprender los procesos de codificación y descodificación en los que se ve involucrado el objeto ${ }^{1}$.

El teórico Gary Burns (1987) propone la subdivisión de los elementos que hacen a la producción de una canción popular en dos categorías: textuales y no textuales. La primera abarcaría la composición musical (ritmo, melodía, armonía) y el texto o la letra; y la segunda correspondería a la performance (instrumentación, tempo, dinámica, improvisación, interpretación vocal) y a la producción de estudio (grabación, mezcla, efectos de sonido, postproducción de audio). Sobre la composición de la letra de una canción, el autor señala dos modalidades: las letras que buscan centrar la atención en el sonido y que utilizarán entonces recursos como la rima, la aliteración, las onomatopeyas y las asonancias; y las letras que ponen el acento en las palabras como artificio poético y que utilizan otros recursos retóricos como la metáfora, la personificación y la parodia. En un tercer lugar Burns distingue otros textos que utilizan otros recursos distintos a los

\footnotetext{
1 Estos dos procesos fueron descriptos en detalle por Stuart Hall en el texto «Codificación y descodificación en el discurso televisivo» (1973). En el proceso de codificación los productores del mensaje emplean un código adecuado a las reglas formales del lenguaje para producir un discurso comprensible destinado a generar un efecto en el auditorio, satisfacer una necesidad o engendrar un uso. En el proceso de descodificación, los receptores del mensaje descifrarán el código partiendo de las estructuras de interpretación y marcos de conocimiento que disponen para producir significados a partir de esos mensajes y adecuarlos a sus propios marcos de referencia y convertirlos en prácticas significativas.
} 
mencionados anteriormente como los giros lingüísticos provenientes de otros idiomas (extranjerismos), el nonsense, los coloquialismos, las obscenidades y blasfemias, las referencias críticas a la industria de la música o a otros músicos y las citas intertextuales con otros marcos de referencia (canciones propias o ajenas, películas, series de TV, libros, etc.).

Desde el punto de vista de la recepción, debemos tener en cuenta tres elementos fundamentales que interactúan en la descodificación del mensaje: al escuchar la letra de una canción oímos a la vez tres cosas: las palabras (texto), la retórica (el uso específico de determinadas palabras en un determinado contexto) y la voz (el signo de la personalidad del cantante). Según Simon Frith (1996) la importancia de las palabras en la letra de una canción está presente no en las ideas sino en los modos de expresión: «proveen al oyente con un medio para articular sus propios sentimientos [...] es lenguaje común adaptado a un contexto de uso extraordinario» (Frith, 1996: 164).

Las canciones son actos de habla (Frith, 1996) y, en consecuencia, las letras adquieren relevancia únicamente en su contexto de enunciación, interactuando con la música y la performance del cantante. No son los componentes individuales de este tipo de comunicación los que dan forma al mensaje, sino la interacción de los tres modos de presentación. Siguiendo la teoría lingüístico pragmática de John Searle (1969) la letra de una canción podría analizarse a partir de la triple clasificación del acto de habla: locutivo (el texto del enunciado), ilocutivo (la intención del acto) y perlocutivo (el efecto sobre el receptor). Este modelo de análisis del que parte también la teoría comunicativa de Stuart Hall es interesante para desarrollar una perspectiva sociolingüística de las letras de las canciones que contemple a la vez una teoría de los lugares comunes (las fórmulas o tópicos comunes y sus variaciones), el modo de exposición formal (el mensaje-forma) y el conjunto de valores sociales de una época.

Los primeros análisis sistemáticos de las canciones populares, especialmente centrados en las composiciones del Tin Pan Alley $^{2}$ y su difusión radial, intentaron generar una tipología de estas fórmulas estandarizadas. De esta manera, J. G. Peatman (1942-43) clasificó a los mensajes en tres tipos: canciones que muestran una experiencia alegre en el amor (happy in love song), canciones sobre el fracaso amoroso (frustrated in love song) y la canción cómica con intereses sexuales (novelty song with sex interest). Una década más tarde, H. F. Mooney (1954), tomando como punto de partida el análisis de Peatman, agregó que las canciones hacen uso de estos tópicos centrales reflejando las necesidades emocionales de su época. Por su parte, S. I. Hayakawa (1955), uno de los

2 Grupo de productores musicales y compositores localizados en Nueva York desde finales del siglo XIX y hasta mediados del siglo XX que tuvieron gran influencia sobre la producción de música popular dentro del período. 
principales cultivadores de la General Semantics, ha dedicado un ensayo a las fórmulas de la lengua y las degeneraciones semánticas en la canción popular norteamericana. Umberto Eco, quien también ha trabajado con la canción de consumo en Apocalípticos e integrados (1965), ha sido uno de los primeros teóricos de la cultura que han abierto el camino al análisis de las formas populares desde una perspectiva semiótico-social.

Nuestra hipótesis sostiene que la canción como unidad narrativa es un género híbrido que toma prestados elementos de otros géneros literarios como la poesía (el metro, el verso y la repetición), el teatro lírico (la apelación directa y empática del cantante a la audiencia) y la novela corta (el modo de organizar la narración con un comienzo, un desarrollo y un desenlace) pero que no existe autónomamente por fuera de la estructura musical y la voz que actúa las palabras. Antoine Hennion (1983) destaca este vínculo entre las partes como una cualidad principal del objeto y argumenta que la canción es como una novela de tres minutos en la que una idea es presentada, elaborada y resuelta a partir de un guión convencional, familiar para el oyente casual -basado en el mito popular- y que opera directamente sobre la memoria y el recuerdo haciendo uso de las posibilidades comerciales de un esquema rítmico repetitivo.

En el presente trabajo intentaremos analizar estos aspectos de la canción popular a partir de la antología de letras de canciones Mother, Brother, Lover (2011) de Jarvis Cocker, anterior miembro, cantante y compositor del grupo inglés Pulp ${ }^{3}$ y ahora solista. En la primera parte discutiremos algunas particularidades de la canción pop como el lenguaje utilizado, la forma estandarizada y el modo de comunicación del mensaje centrado en la coparticipación de música, texto y performance. Para trabajar con este punto nos referiremos a la conferencia «Saying the unsayable», dictada por Jarvis Cocker en el Brighton Festival del año 2008. Nuestro punto de vista sugiere que la estandarización puede ser trabajada de modo tal que el autor pueda filtrar en ella su propia marca distintiva, como en el caso de Jarvis Cocker, cuyo empleo de la repetición es puesto al servicio del desarrollo de su persona dramática ${ }^{4}$.

En el segundo apartado proponemos un análisis de la canción "Common People" siguiendo las pautas expuestas en la primera parte de nuestro trabajo. Y finalmente, nos centraremos en el mensaje mismo de las canciones tratando de revelar su importancia social en el momento presente como discurso social creador y promotor de nuevos mitos y nuevos modos de expresión populares. Al decir que el mensaje de la canción

\footnotetext{
${ }^{3}$ Pulp nace por el año 1983 en Sheffield (Inglaterra) pero es mundialmente conocido en la década del noventa (a partir del año 1994 con la publicación del disco His ' $n$ ' Hers) como parte del estilo Britpop.

${ }^{4}$ Desde el título mismo del libro que proviene de una de las frases más repetidas por el autor en su obra y casi consolidado como marca personal: «That's another thing I've learnt over the years: turn your defects into selling points» (Cocker, 2011: 5)
} 
pop hoy no representa los mismos intereses que en otras épocas históricas no queremos sin embargo sugerir que ésta haya perdido fuerza como discurso social, sino que la evolución del género, en relación directa con la transformación de las estructuras sociales, ha modificado también sus códigos y significados.

\section{El lenguaje, la forma y la función comunicativa}

En el marco del Brighton Festival del año 2008, Jarvis Cocker dictó una conferencia, frente a un auditorio de mil ochocientas personas, sobre las particularidades de la composición de letras de canciones populares. Su discurso fue acompañado por diversos ejemplos musicales trazando un esquema argumentativo fundado en la siguiente hipótesis: las letras aisladas del contexto de la canción (música y performance) pierden su significado original que procede de la suma de las partes: «Las letras de las canciones no son poesía: son palabras al servicio de la canción» (Cocker, 2011: 3).

Pensemos, siguiendo la afirmación de Jarvis Cocker, en la canción pop como un enunciado estable e intentemos una primera definición del género ${ }^{5}$ : la canción pop es una fórmula basada en la repetición, cuyo contenido verbal solo cobra importancia y es recordado al ser inmediatamente asociado a una melodía y a un esquema rítmico determinado. Esto quiere decir que: 1) las palabras sin la música (aisladas del contexto de la canción) pierden su comunicabilidad; y 2) la fórmula de la canción pop como estructura estable permite que la comunicación del mensaje sea eficaz.

Como mencionábamos anteriormente, Cocker afirma que las letras se diferencian de la poesía porque no son formas independientes, sino parte de un sistema. Pero además, la lírica de una canción se distingue de la poesía porque está sujeta a otras reglas formales: tolera especialmente la repetición porque su objetivo consiste precisamente en captar la atención del oyente una y otra vez. Esta principal diferencia entre la poesía y la letra de una canción se hace evidente cuando los letristas trabajan la transposición de textos poéticos al formato canción. Hablamos precisamente de una transposición y no de un traslado directo porque el texto tendrá que ajustarse a una nueva forma ${ }^{6}$. En la mayoría de los casos las modificaciones sobre el hipo-texto poético tienden a acortar los textos originales y colocar el énfasis en el estribillo, adaptando

\footnotetext{
5 Entendiendo «género» en el sentido bajtiniano del término como un tipo estable de enunciado característico de un uso particular de la lengua en una esfera social determinada.

${ }^{6}$ Un ejemplo de esta última tarea de transposición es la versión de Frank Sinatra de la canción "On the Road to Mandalay” sobre el poema de Rudyard Kipling "Mandelay" (1892).
} 
también el lenguaje a un registro coloquial $^{7}$ (o actualizando las expresiones). Debe entonces ajustarse el texto a la estructura fundamental de la canción popular: versoestribillo-verso.

$\mathrm{Si}$, como dijo Wright Mills en White Collar, en la sociedad de masas la fórmula substituye a la forma y la fórmula precede a la forma (a la invención, a la propia decisión del autor), el campo de la música de consumo se presenta como modelo típico (Eco, 1965: 316).

Este modelo típico, en términos de Umberto Eco, fundado en las leyes de la repetición y en la objetividad de la forma señala otra característica de la canción, como bien de consumo, siguiendo una serie de recursos que la hacen vendible $^{8}$ : «no revelándonos algo nuevo, sino repitiéndonos lo que ya sabíamos, que esperábamos ansiosamente oír repetir y que nos divierte» (Eco: 317). No obstante, la simplificación de la estructura y del esquema rítmico de la canción podría también permitir al artista jugar con la ambigüedad entre lo repetido una y otra vez -la fórmula- y la novedad o la sorpresa, quizás (en el orden del relato) un nuevo estilo de escritura, un nuevo uso del lenguaje o una historia original. Una de las habilidades del letrista contemporáneo es trabajar con la ironía, la parodia o el humor, intentando que por medio del extrañamiento de los elementos típicos (en algunos casos como crítica de la misma estandarización de la música pop) se impida el agotamiento de la fórmula.

Jarvis Cocker habla también en su conferencia acerca del tratamiento de temas inadecuados (inappropriate) por parte de la literatura de la canción popular contemporánea. Canciones como «Heroin», de la Velvet Underground, o «Louie Louie» ${ }^{9}$, de The Kingsmen (1963), reflejan la importancia de los tópicos prohibidos a nivel social que encuentran un canal de expresión en la canción popular. Estableciendo una distante analogía con la descripción bajtiniana del carnaval en la Edad Media, podríamos decir que la canción popular, como forma de la cultura, ofrece «una visión del mundo, del hombre $y$ de las relaciones humanas totalmente diferente, deliberadamente no-oficial» (Bajtín, 1941:11). La canción es percibida como un espacio de liberación de las reglas que rigen el mundo, una excepción a la norma, una marca de desterritorialización.

\footnotetext{
${ }^{7}$ Según Simon Frith las letras de las canciones emplean «un lenguaje habitual con un uso excepcional» (1996: 167). El lenguaje coloquial utilizado en las letras de las canciones es otro signo de parentesco con los géneros discursivos primarios como la conversación o el diálogo cotidiano.

${ }^{8}$ Lo que vende: a) un ritmo ligero y bailable; b) una melodía que permanece en la memoria de la gente; c) una letra que promueve la acción dramática, o define el punto de vista del personaje, el lugar de la persona (Burns, 1987: 2)

${ }^{9}$ La canción fue objeto de una investigación del FBI por el contenido obsceno de la letra. El caso fue cerrado declarando que el contenido era incomprensible: «unintelligible at any speed». Puede leerse más sobre el tema en «Combating Merchants of Filth: The Role of "Louie Louie"» (Marsh, 1993)
} 
Este último ejemplo trae a colación un problema que relaciona el mensaje de la canción con el uso particular de la lengua en la oralidad. La canción es una forma cercana a la conversación. Por esto mismo su naturaleza no es atemporal y su evolución está sujeta al recambio de expresiones y modos de organizar enunciados para describir situaciones, objetos o personas: habla en el idioma de la moda porque necesita el reconocimiento inmediato del oyente. De la misma manera, la canción prefiere la forma narrativa porque el esquema básico del relato breve de ficción es un código textual que forma parte del marco de conocimiento común del oyente: «Las letras [...] nos presentan a las canciones como historias. Todas las canciones son narrativas implícitas [...] solo pueden ser introspectivas si el yo en la canción es ficticio» (Frith, 1996: 169).

En el prólogo a Mother, Brother, Lover, Jarvis Cocker habla de este modo de escribir la letra de una canción que consiste en tomar como punto de partida una experiencia personal e introducir elementos ficcionales que ayuden a desplazar la biografía del yo por otra cuya única existencia es textual. El sujeto se desdobla así en otra voz ajena, que será interpretada en escena por una máscara y que será repetida incontables veces por otras voces plurales -las de la audiencia- que se apropian del mensaje y asumen el yo desde otra perspectiva.

Un ejemplo de este procedimiento lo encontramos en «Live Bed Show». La idea o motivo principal del texto de la canción nace relacionada con un objeto y ese objeto con la biografía del autor: una cama comprada en segunda mano que marcó el momento de salida de Jarvis Cocker de su ciudad natal (Sheffield) y el establecimiento en un nuevo ámbito (Londres) ${ }^{10}$. Tras una segunda mudanza a un piso amueblado, la cama fue donada a un amigo y años después, al tiempo presente de la escritura de la letra de la canción (1997), luego de un tercer cambio de residencia y la adquisición de una vivienda propia, el objeto reaparece en la vida de Jarvis Cocker. El tema de la canción contiene la pregunta ¿de qué historia/s pudo haber sido parte esa cama en el tiempo de ausencia?

She doesn't have to go to work but she doesn't want to

stay in bed 'cos it's changed from something comfortable to something else instead (Pulp, 1995c).

(Ella) no tiene que ir a trabajar pero tampoco quiere

quedarse en cama porque ha dejado de ser algo confortable para ser algo distinto.

La cama como objeto está cargado de un doble significado: es un mueble más de la casa que ha dejado de ser útil pero si esta utilidad del objeto como bien de consumo se traslada al campo semántico de la relación amorosa entonces sugiere una pérdida de valor (la pérdida de la comodidad) por la pérdida de actividad, quizás la pérdida erótica.

\footnotetext{
${ }^{10}$ Identificado también con diferentes momentos de su carrera artística en ascenso.
} 
El pronombre She (ella) sugiere una ambigüedad lingüística al proponer una doble referencia, o bien la cama personificada o bien un personaje femenino de la historia. Otra cita del texto de la canción:

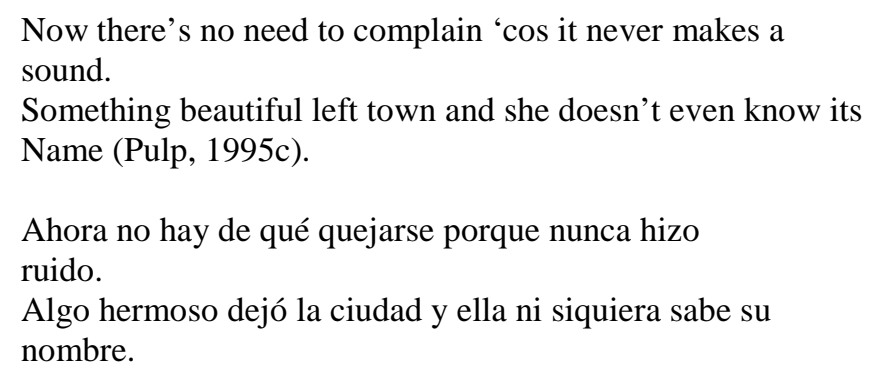

A la inversa, esta estrofa comienza hablando de la cama y continúa hablando de la protagonista de la historia narrada (mencionada en tercera persona, es decir hablada a su vez por una voz ficcional). El pronombre posesivo its (su) refiriéndose a un objeto que podría ser la cama tiene sin embargo un nombre (el que ella desconoce) y sugiere, ahora, que «eso» podría ser él/ella, aludiendo a una cosificación de la persona como objeto sexual (y a la vez sin marca de sexo ni nombre).

Al otorgar una voz a la canción y un personaje a la historia, junto con el procedimiento doble de personificación y cosificación, Jarvis Cocker desdibuja las fronteras entre el referente real (el disparador objetivo de la escena y la relación que establece ese objeto con su persona real) y el producto de la escena narrada como ficción. El texto se hace entonces impersonal, preparado para ser reapropiado por cualquier oyente del público que volverá a cargar de significado los pronombres vacíos con valores personales.

Este traslado de la voz del sujeto como máscara (del sujeto en actuación, en performance) al público cumple con la doble función de la canción popular como divertimento y como catarsis. Para que esta última comunicación entre el cantante y el auditorio sea exitosa, la puesta en acto de la ecuación música-texto-performance debe hacer coincidir a la vez lo que Barthes (1977) denomina el pheno-texto y el geno-texto, la confraternidad de la performance del artista puesta al servicio de la comunicación, representación y expresión de valores culturales vigentes (tanto para afirmarlos como para rechazarlos) y de la materialidad de su propia voz como significante, su cuerpo en la música, su dicción. En esta confluencia, la individualidad o la subjetividad del artista buscarán su lugar de expresión dentro de la fórmula estandarizada (estructural o temática) de la canción. 
F.E.E.L.I.N.G.C.A.L.L.E.D.L.O.V.E: Una aproximación a la teoría...

\section{Un ejemplo de análisis}

En el apartado anterior hacíamos referencia a la forma estandarizada de las canciones. La canción se estructura habitualmente usando entre tres y cinco secciones musicales separadas: introducción, verso, estribillo, verso, estribillo y puente musical, seguido de una repetición continuada del estribillo hasta el silencio final. Este será el primer punto de análisis que tomarán los musicólogos para trabajar con una canción desde el análisis formal. Dirán si se ajusta o no a los parámetros de la fórmula y qué recursos musicales (escalas, armonías, temas melódicos, intensidades, efectos de sonido, variaciones y modulaciones) utilizan para marcar las continuidades y rupturas dentro del esquema presentado. Los filólogos, en cambio, preferirán realizar un análisis de las letras a partir de las herramientas que ofrece el análisis literario focalizándose en el contenido en detrimento de la forma. Ahora, ¿cómo trabajar con canciones populares como las de Jarvis Cocker que colocan el acento en la unión de la estructura convencional de la canción pop con el tratamiento de temas inapropiados? Como argumentábamos anteriormente, nuestra teoría es que todas las canciones al ser construidas con elementos intersemióticos involucran de algún modo este tipo de relación entre forma musical y contenido textual y que de un modo u otro la codificación del mensaje de una canción juega con la polaridad de los dos componentes, y, sumado a ello, con la dicción de la voz en la puesta en acto.

Nuestra propuesta en este apartado es ofrecer un ejemplo de análisis del texto «Common People», en función de los lineamientos teóricos que hemos trazado. La canción comienza así:

\footnotetext{
She came from Greece, she had a thirst for knowledge. She studied sculpture at St. Martin's College: that's where I caught her eye.

She told me that her dad was loaded.

I said, 'In that case I'll have a rum and Coca-Cola'

She said, 'Fine' -and then in thirty seconds' time she said:

'I want to live like common people,

I want to do whatever common people do,

I want to sleep with common people,

I want to sleep with common people like you'

Well, what else could I do?

I said, 'I'll see what I can do' (Pulp, 1995c).

Ella venía de Grecia y tenía sed de conocimiento.

Estudiaba escultura en St. Martin's College: ahí es adonde yo la vi.

Me dijo que su padre estaba forrado.

Le dije, 'en ese caso tendré ron y Coca Cola'

Me dijo, 'bien' -y entonces en treinta segundos me dijo:

'Quiero vivir como la gente común,

quiero hacer lo que la gente común hace,

quiero dormir con gente común,

quiero dormir con gente común como vos'
} 
Lo primero que destacaremos del fragmento citado es el estilo narrativo. El narrador de la canción, personaje creado por Jarvis Cocker que puede o no coincidir con la persona real pero que en el acto performativo se establece como identidad autónoma, utiliza fundamentalmente la cita directa para reconstruir la escena y el diálogo entre los personajes involucrados. En los primeros tres versos se describe el contexto general de la historia contada, con una primera descripción del personaje femenino (ella es griega, es estudiante de escultura y tiene sed de conocimiento) y de la relación que tiene con el narrador: él también estudia en St. Martin's College y allí se conocieron. En estas tres líneas se acentúa el pronombre de tercera persona femenino She (ella) con dos descripciones contextuales y una cita indirecta que inmediatamente después es interrumpida por el pronombre de primera persona $I$ (yo) y la introducción del diálogo. Las siguientes tres líneas de la canción sugieren el problema principal (ella es de buena familia, su padre tiene mucho dinero) que se explicita luego en la séptima línea: «Quiero vivir como la gente común». En este punto comienza la repetición que, a los fines estructurales de la canción (articulando letra y música) constituye el hook o la frase anzuelo (eslogan que capta la atención del oyente casual y se graba en la memoria). Las dos últimas líneas son formalmente una coda de la frase principal y representan una reflexión del narrador sobre la tentativa de resolución del problema: «veré qué puedo hacer».

La siguiente estrofa imita la estructura de la primera y establece una relación intertextual y un juego de pronombres y significados. Así, las primeras tres líneas invierten el orden de aparición de los pronombres presentado en la primera estrofa, poniendo el acento en el $I$ (yo) frente al She (ella) utilizado anteriormente:

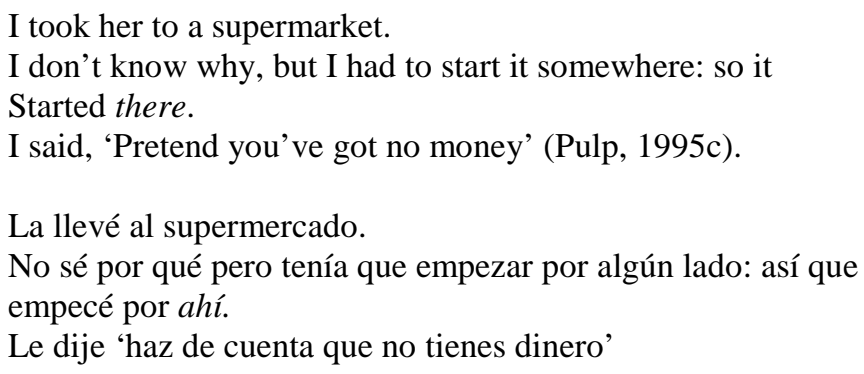

Además del juego de pronombres se suma la oposición de campos semánticos: en la primera estrofa los lugares referidos son «Grecia»y «St. Martin's College», contrastados ahora con el ámbito del supermercado. Finalmente, la afirmación «Haz de cuenta que no tienes dinero» se opone a la tercera línea de la primera estrofa: «Me dijo que su padre estaba forrado». 
F.E.E.L.I.N.G.C.A.L.L.E.D.L.O.V.E: Una aproximación a la teoría...

Las siguientes citas directas presentan las mismas características:

She just laughed and said, 'Oh, you're so funny'. I said,

'Yeah? Well, I can't see anyone else smiling in here' (Pulp, 1995c).

Solo rió y dijo 'eres tan gracioso'. Le dije

¿Sí? Bueno, yo no veo a nadie más aquí que esté riendo’

En este caso «eres tan gracioso» refiere tanto a la frase que le precede como a la frase que ocupa la misma posición en la estrofa anterior: «en ese caso tendré ron y Coca-Cola»y de igual manera «Bien» en la primera repite el «Sí̀ de la segunda. Ambas estrofas mantienen una relación especular centrando la figura en el personaje femenino y en el personaje masculino -asumido por la voz cantante- casi configurando un montaje cinematográfico de planos alternos.

La estructura interna de estas dos primeras estrofas es la siguiente:

\begin{tabular}{|l|}
\hline Introducción (primeras tres líneas): estilo recitativo / función contextual \\
\hline Verso recitativo (siguientes tres líneas): estilo recitativo / función predicativa \\
\hline Refrán o hook: frase principal con función dramática \\
\hline Verso recitativo (últimas dos líneas): estilo recitativo / función reflexiva \\
\hline
\end{tabular}

La canción continúa con un puente (bridge) en el que tanto la música como la letra cambian. La función de esta tercera sección (diferente al verso recitativo y al estribillo) es intensificar el mensaje a partir de la dramatización. Dividido en dos partes, primero se dan las opciones condicionales (esto es lo que tienes que hacer si quieres vivir como la gente común) y luego se niega la posibilidad, produciendo un contraste irónico entre la intensidad dramática de la música y el significado del mensaje:

Rent a flat above a shop

Cut your hair and get a job

Smoke some fags and play some pool

Pretend you never went to school

But still you'll never get it right

'cos when you're laid in bed at night watching roaches climb

the wall

if you called your dad he could stop it all (Pulp, 1995c).

Alquila un piso sobre una tienda

Córtate el cabello y consigue un trabajo

Fuma cigarrillos y juega al pool

Actúa como si no hubieras ido al colegio

Aun así nunca lo entenderás

porque cuando estés tirada en la cama viendo a las cucarachas trepar

por la pared

llamarías a tu padre y él podría detenerlo todo. 
En esta parte de la canción la rima es el recurso enfático principal. Concatena los versos por pares agrupando las frases y marcando las oposiciones de sentido entre las palabras rimadas al final del verso (shop/job - tienda/trabajo; pool/school - pool/colegio) y en el medio (flat/fags - piso/cigarrillo). Y junto con la repetición del estribillo, la rima captura la atención del oyente y apela a la memorización del contenido, lo hace cantable. El cambio a la rima (en lugar de continuar el esquema de la repetición del estribillo) junto con la variación musical (no se produce un cambio en la secuencia armónica pero sí en la melodía), evitan la monotonía y preparan para volver al esquema estribillo/verso final repetido dos veces y con cambios en la letra, pero manteniendo el acento en el enunciado «common people». Aunque no se manifiesten alteraciones en la línea melódica, la variación de la letra y de la intensidad (musical y de dicción) producen un efecto in crescendo que representa un clímax en la repetición misma. A su vez, en el estribillo se utiliza la negación repetida, cambiando el motivo de la primera parte afirmativa:

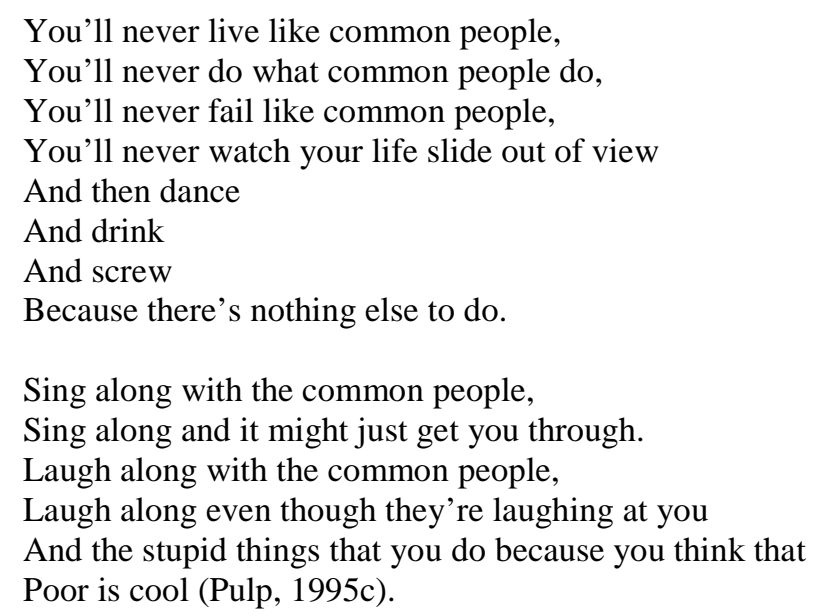

Nunca vas a vivir como la gente común nunca vas a hacer lo que la gente común hace nunca vas a fracasar como la gente común nunca vas a ver tu vida fuera de foco y luego bailar y beber

y follar porque no hay nada más que hacer

Canta junto a la gente común canta y puede que te dejes llevar. Ríete junto a la gente común ríete aunque estén riéndose de ti y de las tonterías que haces porque piensas que ser pobre está de moda.

La canción podría terminar en este punto. La situación inicial, el planteo del problema, el intento de solución y la sentencia negativa fueron todos expuestos -la 
F.E.E.L.I.N.G.C.A.L.L.E.D.L.O.V.E: Una aproximación a la teoría...

versión del videoclip de la canción termina justamente aquí por motivos exclusivamente comerciales $^{11}$ - pero en la versión del álbum Jarvis Cocker continúa repitiendo y alternando los esquemas anteriores para desequilibrar el balance de la historia y volver ridículamente frustrante el intento del personaje femenino por pertenecer a la clase de gente común. Esta condición continúa alternando el esquema estribillo / verso con el puente hasta finalizar con una secuencia repetida en fade out: «I wanna live like common people like you» volviendo a la frase principal (citando lo que ella dijo) y convirtiéndola en un refrán que haciendo uso de la repetición va despojándose de sentido a medida que la canción se termina.

\section{Mitologías de la vida cotidiana}

Entiendan. No queremos causar problemas.

Solo queremos tener derecho a ser diferentes. Eso es todo.

Pulp. Different Class (Polygram, 1995)

No solo el lenguaje utilizado sino también los principales temas involucrados en la composición de las letras se relacionan con la vida cotidiana ${ }^{12}$. La canción es un espacio de reflexión sobre el modo de experimentar el amor $^{13}$ y las relaciones con el sexo opuesto, sobre lugares y objetos de conocimiento común; son narrativas de la experiencia y conforman una poética de la vida cotidiana.

Fue el comienzo de un tipo de sensibilidad, un deseo de explorar los lugares no tan obvios - porque estaban justo frente a ti. 'Pulp"14: el lugar perfecto para hacerlo porque representaba el intento de encontrar significado a los objetos descartables de producción en masa que circulan a diario (2011: 7)

Roland Barthes afirma que todo mito constituye un sistema de comunicación, un mensaje y, en consecuencia, «si el mito es un habla, todo lo que justifique un discurso puede ser mito» (1957: 199). El mito opera desplazando de nivel a una primera significación y estableciéndose como metalenguaje de un sistema semiótico preexistente: «al devenir forma, el sentido aleja su contingencia, se vacía» (Barthes, 1057: 209).

\footnotetext{
${ }^{11}$ El formato comercial de una canción debe respetar el tiempo promedio de tres minutos. Otra diferencia entre las dos versiones es la omisión del verbo screw que en el videoclip y en el radio-edit fue censurada, no así en la versión del álbum.

${ }^{12} \mathrm{Y}$ lo hacen de manera ambigua porque parten de la opinión común para luego criticarla pervirtiendo todo intento de homogenización del gusto.

13 «Terminé documentando mi propia adolescencia a través de las canciones que componía» (Cocker, 2011: 2).

14 Jarvis Cocker se refiere a las «revistas de pulpa» o pulp popularizadas como género narrativo y de historieta.
} 
Desde mediados de la década del sesenta la función de las letras de las canciones de rock ha sido exponer la (falsa) ideología sentimental de la sociedad capitalista (el modo en el que las canciones de consumo masivo describen las banalidades del amor). Frente a este romanticismo, la tradición del rock ha recuperado el realismo del blues para manifestarse. La teoría del realismo en la lírica de la canción implica que existe una relación directa entre el texto y la condición social o emocional que describe o representa (Frith: 1988, 112). El movimiento contrario a la naturalización del mito es en este caso canalizado como una vuelta a la historia. Pero la decadencia de un sistema mitológico determinado no implica necesariamente esta salida. Puede también -y es seguro que lo hará- renovar sus formas.

En este contexto cobra sentido el argumento de Jarvis Cocker en el prólogo de Mother, Brother, Lover en el que señala la discrepancia entre el modo en que las canciones hablaban del amor en la radio y la forma en la que él mismo lo experimentaba. Puesto en otros términos, cuando la oferta de música de consumo masivo no cumple con la función catártica en todos los oyentes, y el tratamiento generalizado de los tópicos comunes no satisface a un sector de la audiencia, los artistas primero y la industria después intentarán popularizar una nueva serie de valores y una nueva mitología.

Al afirmar Jarvis Cocker que las letras de Pulp proponen una sensibilidad fundada en «el deseo de mirar en los lugares menos evidentes», lo que cuestiona no es la capacidad de la cultura popular de convertir sus discursos en un habla despolitizada, sino la pérdida de actualidad y representatividad del modo de expresión del lenguaje mítico vigente. El intento de Jarvis Cocker de «crear el tipo de música pop que hubiera querido tener cuando lo necesitaba» es un reflejo de esta necesidad de producir nuevas mitologías populares. Las letras de sus canciones tienen su fundamento en esta afirmación.

Por mencionar un breve ejemplo, en la letra de «Mis-shapes» Cocker traslada elementos del entorno cotidiano a un nuevo sistema de significados, borrando el concepto primero (que en este texto en particular ya viene derivado de otro) y convirtiéndolo en forma de un significado segundo. Analicemos la operación:

\footnotetext{
Raised on a diet of broken Biscuits (Pulp, 1995b).

Criado en una dieta de galletas rotas
}

La tienda de dulces que estaba situada enfrente de la casa adonde pasó su infancia Jarvis Cocker vendía bolsas de chocolates de oferta (chocolates de aspecto irregular que no se consideraban aptos para empaquetar) etiquetados como «mis-shapes». En la frase citada el autor construye una equivalencia entre las galletas rotas y esos chocolates y 
más adelante en el texto, estos «mis-shapes» representarán a un tipo social específico, un estereotipo arraigado en la cultura del rock: el outsider.

\begin{abstract}
We weren't supposed to be -we learnt too much at school, now we can't help but see that the future that you've got mapped out is nothing much to shout about (Pulp, 1995b).

No tendríamos que haber existido -aprendimos demasiado en la escuela, ahora no podemos evitar ver que vuestro futuro diseñado no tiene nada de otro mundo.
\end{abstract}

El título de la canción representa así una ambigüedad estructural y semántica. En el recorrido del texto, acompañado de la música y la presencia individual de la voz cantante, el significado de «mis-shapes» como dulces rebajados de precio desaparece, dejando un lugar vacío que será completado con otro concepto, el adolescente idealista y crítico desplazado de los valores que rigen el mundo que lo rodea ${ }^{15}$.

En el mito se encuentran las cinco exigencias que Umberto Eco describe en su texto «La canción de consumo» (1965: 331) ${ }^{16}$. Por un lado permite la idealización e intensificación de la vida cotidiana y la sacudida catártica que canaliza el instinto agresivo y violento del adolescente outsider: las letras de las canciones que tratan del estereotipo serían un medio de expresión de las emociones reprimidas contra las presiones que impone el modo de vida alienante de la sociedad moderna. Y además, la identificación con el mito promovería la evasión del adolescente -del mundo construido por adultos- por la delimitación de un espacio propio, fundado en la diferencia.

\title{
5. Conclusión
}

Partiendo de un corpus de canciones, todas ellas de la antología de letras del cantautor inglés Jarvis Cocker, hemos intentado en nuestro trabajo arribar a un modelo posible de análisis de la canción popular contemporánea. A lo largo de nuestro trabajo hemos planteado una serie de interrogantes sobre la naturaleza formal y textual de las canciones pensadas como mensajes que han de ser comunicados.

En ningún momento hemos puesto en tela de juicio la profundidad (o el valor ético/estético) de los mensajes de esas canciones. Esto se debe a que nuestro objetivo ha sido en cierta medida cuestionar la crítica negativa de la cultura de masas. Creemos a su vez que es posible, y muchos teóricos de la cultura popular lo han confirmado en las

\footnotetext{
${ }^{15}$ Un estudio interesante sobre la caracterización del outsider en el contenido de las letras de canciones populares puede leerse en Popular Music Perspectives. Ideas, Themes and Patterns in Contemporary Lyrics (Cooper, 1991: 37-48)

${ }^{16}$ Umberto Eco se refiere al mito Rita Pavone, que representa un estereotipo en algunos aspectos distinto al outsider. Sin embargo, lo que quiere destacar Eco del mito de la canción de consumo es el hecho de que «hace que los problemas de la adolescencia se mantengan en una forma genérica» (331).
} 
últimas décadas, tomar a las canciones como objetos de investigación que merece un campo de estudio y una metodología propia, intersemiótica, interdisciplinaria y comparativa.

En cuanto a los mensajes de las canciones, lo importante no es lo que se dice (el análisis del contenido), sino de qué modo se transmite, cómo se articula la comunicación y qué modos de expresión se utilizan. Decíamos junto a Simon Frith que las canciones son actos de habla mediante los cuales un discurso es codificado y descodificado por el público dentro del circuito de la cultura.

Al comenzar nuestro trabajo considerábamos necesario abordar el análisis de los mensajes de la cultura popular desde dos puntos de vista: uno centrado en el momento de la producción y otro desde la recepción. En nuestro ejemplo de análisis, sin embargo, hemos puesto el foco sobre el primero sin hablar demasiado del segundo. Antes de terminar, entonces, diremos que es importante sumar a este modelo de análisis de la canción pop los discursos secundarios que hablan de ella, los discursos de quienes emiten juicios de valor -los oyentes, los periodistas y otros músicos-. Estos enunciados son la clave para comprender la importancia social de los textos de la cultura popular en contexto y para estudiar el modo en el que se descodifican y reproducen los significados.

\section{Bibliografía}

BAJTíN, M. (1941): La cultura popular en la Edad Media y el Renacimiento. El contexto de François Rabelais. Trad. Julio Forcat y César Conroy. Madrid, Alianza, 1987.

(1952-53): «El problema de los géneros discursivos», en Estética de la creación verbal. Trad. Tatiana Bubnova. México, Siglo XXI, 1995, pp. 248-294.

BARTHES, R. (1957): Mitologías. Trad. Héctor Schmucler. México, Siglo XXI, 2009.

- (1977): «The grain of the voice», en Image, music, text. Trad. Stephen Heath. Nueva York, Hill and Wang, pp. 179-89.

BURNS, G. (1987): «A Typology of "Hooks" in Popular Records», Popular Music, 6/1, pp. 1-20.

COCKER, J. (2008): «Saying the unsayable» en http://www.acrylicafternoons.com/ jarvisonsong.html (última consulta: 21-2-2012).

(2011): Mother, Brother, Lover. Londres, Faber and Faber.

ECO, U. (1965): Apocalípticos e integrados. Trad. Andrés Boglar. Barcelona, Lumen, $7^{\mathrm{a}}$ ed., 1984.

FRITH, S. (1996): Performing Rites. On the Value of Popular Music. Oxford, Oxford University Press. 
HALL, S. (1973): «Codificación y descodificación en el discurso televisivo». Trad. Ana I. Segovia y José Luís Dader, Cuadernos de Información y Comunicación, 9 (2004), pp. 210-236.

HAYAKAWA, I. S. (1955): «Popular songs vs the facts of life», Etc, 12, pp. 83-95.

HENNION, A. (1983): «The production of success: an anti-musicology of the pop song», en S. Frith y A. Goodwin, eds, On Record. Nueva York, Pantheon Books, 1990, pp. 185-206.

COOPER, B. L. (1991): Popular Music Perspectives. Ideas, Themes and Patterns in Contemporary Lyrics. Ohio, Bowling Green State University Popular Press.

MARSH, D. (1993): Louie Louie. Nueva York, Hyperion.

MOONEY, H. F. (1954): «Song, singers and society. 1890-1954», American Quarterly, 6, p. 226.

PEATMAN, J. G. (1942): «Radio and Popular Music», en P. F. Lazersfeld and F. Stanton, eds., Radio Research. Nueva York, Duell, Sloan and Pearce.

PULP (1995a): «Common People», Different Class [disco compacto], Polygram.

- (1995b): «Mis-Shapes», Different Class [disco compacto], Polygram.

- (1995c): «Live Bed Show», Different Class [disco compacto], Polygram.

SEARLE, J. (1969): Actos de habla. Ensayo de filosofía del lenguaje. Trad. Luis Valdés Villanueva. Madrid, Cátedra, 1994. 